\title{
DISPOSAL OF SURPLUS WEAPONS GRADE PLUTONIUM
}

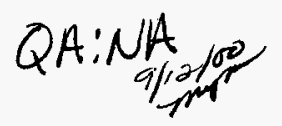

\author{
Halim Alsaed \\ Framatome Cogema Fuels. \\ 1211 Center Crossing Road \\ Las Vegas. NV 89144. \\ (702)295-3437
}

\author{
Peter Gottlieb \\ TRW \\ 1211 Center Crossing Road \\ Las Vegas. NV 89144. \\ (702)295-4381
}

\section{Introduction and Background}

The Office of Fissile Materials Disposition is responsible for disposing of inventories of surplus U.S. weapons-usable plutonium and highly enriched uranium as well as providing, technical support for, and ultimate implementation of, efforts to obtain reciprocal disposition of surplus Russian plutonium.

On January 4, 2000, the Department of Energy issued a Record of Decision ${ }^{(1)}$ to dispose of up to 50 metric tons of surplus weapons-grade plutonium using two methods. Up to 17 metric tons of surplus plutonium will be immobilized in a ceramic form, placed in cans and embedded in large canisters containing high-level vitrified waste for ultimate disposal in a geologic repository. Approximately 33 metric tons of surplus plutonium will be used to fabricate MOX fuel (mixed oxide fuel, having less than $5 \%$ plutonium239 as the primary fissile material in a uranium-235 carrier matrix). The MOX fuel will be used to produce electricity in existing domestic commercial nuclear reactors.

This paper reports the major waste-package-related, long-term disposal impacts of the two waste forms that would be used to accomplish this mission. Particular emphasis is placed on the possibility of criticality. These results are taken from a summary report published earlier this year ${ }^{(2)}$.

\section{General Methodology}

There is no possibility of a criticality while the waste package and waste forms are intact. As the waste form and waste package degrade over tens of thousands of years, the probability of physical separation between neutron absorber and fissile material may increase, rendering the neutron absorber ineffective for the purpose of preventing criticality.

Any degradation scenario leading to criticality must include the following three processes: breach of the waste package and flow of water through the package; corrosion of the material that carries the neutron-absorber elements, and loss of those elements from the waste package; and the accumulation of sufficient water within the waste 
package to serve as moderator. For external criticality the required second and third processes are the dissolution of the fissile material and its transport out of the waste package, and the collection/accumulation of the fissile material transported by the solution flowing out of the waste package.

This analysis methodology also accounts for the manner in which these processes can be influenced by natural events (particularly seismic disturbance and igneous intrusion). The results of these analyses will be presented in terms of the possible critical configurations and the probability that the waste package, or its contents will achieve criticality. We also evaluate the possibility for external criticality that could result from the $\mathrm{Pu}$ ceramic waste form.

\section{Impacts of Disposal of the MOX Waste Form}

The analyses for the MOX waste form are based on the PWR MOX fuel cycle specified in recent report by Westinghouse ${ }^{(3)}$, with the spent fuel assemblies placed in the standard CRWMS waste packages for pressurized water reactor (PWR) fuel assemblies. The fuel cycle actually implemented will be specified by the contractor that has been selected to fabricate this fuel using the surplus weapons plutonium. The licensing of the resulting spent nuclear fuel (SNF) will require analyses specific to that cycle. The analyses that have been performed demonstrate that the MOX behavior is very similar to that of the LEU (low-enriched uranium) PWR SNF. The MOX waste form was evaluated in the following four ways:

Thermal impacts: The thermal load of the MOX waste packages is within the envelope of the commercial SNF using LEU; therefore, it can meet all repository requirements.

Structural impacts: For the worst-case structural accident (waste package tipover) the calculated stresses on the waste packages containing MOX SNF are very similar to stresses calculated for waste packages containing ordinary LEU SNF. This result is to be expected because the MOX and ordinary commercial assemblies have nearly the same weight and design.

Radiation shielding impacts: Maximum dose rates from the MOX SNF were much lower than those from commercial LEU PWR SNF of similar burnup.

Probability of criticality: A likely degradation scenario for the commercial PWR waste package is shown in Figure 1, as a sequence of the six configurations that characterize the degradation process. 


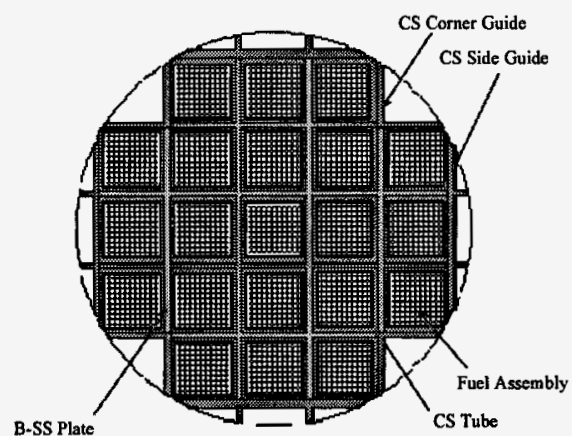

A) Initial Configuration

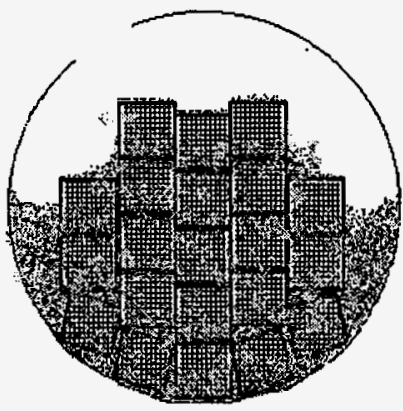

D) Fully Degraded Basket with Intact Assemblies

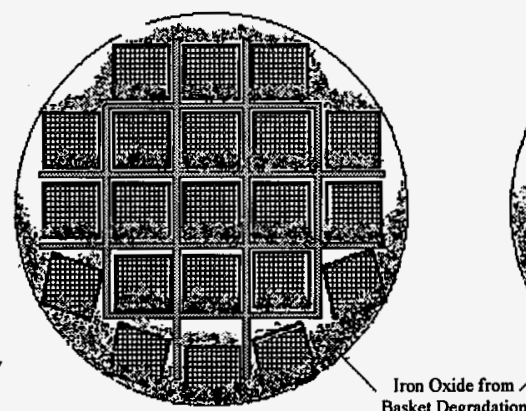

B) Side and Corner Guide Failure

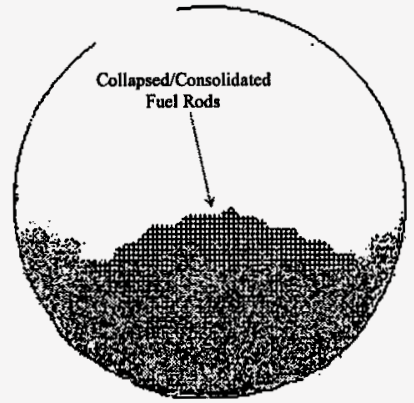

E) Fully Degraded Basket and Assembly Structure Intact Fuel Rods

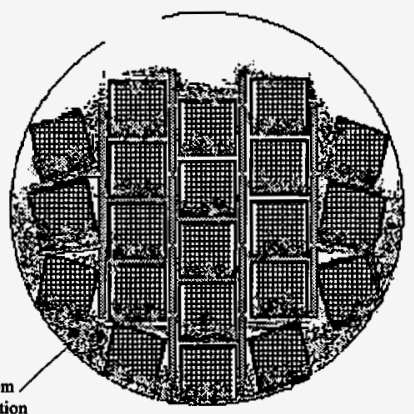

C) Fully Collapsed Basket

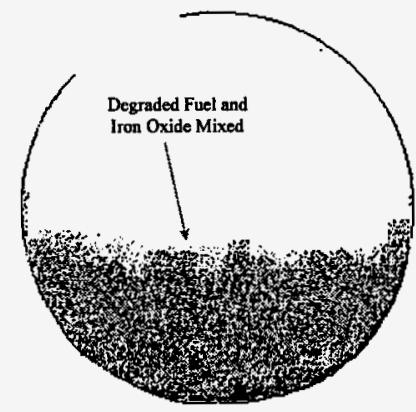

F) Fully Degraded Basket and Fuel

Figure 1. Degradation Sequence of the 21 PWR Basket Structure Following Breach of a 21 PWR Waste Package

Configuration $\mathrm{D}$ has the highest $\mathrm{k}_{\mathrm{eff}}$ of these six configurations because the primary criticality-control neutron absorber, boron, has been dissolved and transported out of the waste package while the fuel pins are still separated by the basic assembly pitch, so that they are susceptible to nearly optimum water moderation. This configuration presents some criticality problem for approximately $10 \%$ of the commercial LEU SNF that has had significantly less than the normal burnup. Such SNF has more fissile material remaining and does not have sufficient neutron-absorbing fission products, so some added neutron absorber, like boron, is needed to provide criticality control.

However, all of the MOX SNF is expected to have normal burnup, which will provide sufficient neutron absorbing fission products to prevent criticality. Therefore, the only way for the MOX SNF to become critical is through a very unlikely variant of Configuration $\mathrm{D}$, in which most of the fission products, and/or the iron oxide have been dissolved and transported out of the waste package. This transport out of the waste package is extremely unlikely because of the very low solubility of both iron oxide (in the most long-term stable ferric oxidation state) and most of the neutron absorbing fission 
products.

Even this scenario has a very low probability because when all possibilities are considered and weighted according to conservative estimates of probability, the expected number of criticalities, internal to the waste package in 100,000 years is less than 0.08 .

There is no credible scenario leading to external criticality from a MOX waste package because of several physical effects. First, the concentration of fissile material in any water flowing out of the waste package is very small. Second, because the waste package is designed to resist corrosion so strongly that no aqueous breach can occur at all before 10,000 years, and is extremely unlikely to occur before 50,000 years, most of the plutonium-239 will have decayed to the less reactive (but still fissile) uranium-235. Finally, in addition to being less reactive than the plutonium-239, the uranium-235 transported out of the waste package will be accompanied by the chemically identical uranium-235, which is a significant neutron absorber.

Consequences of steady-state criticality: A worst-case steady-state criticality in a single waste package could last up to 10,000 years (the typical duration of a wet climate cycle that could have a large enough drip rate to exceed the evaporation rate due to the steadystate criticality). The maximum radionuclide inventory increment at 1,000 years following the criticality shutdown would be $18 \%$ of the radionuclide inventory (in Curies) that would have been present at that time without the criticality. At 20,000 years following the criticality shutdown the radionuclide inventory increment will have decayed to only $2.5 \%$ (in Curies) more than would have been present without the criticality.

Consequences of a transient criticality: A transient criticality can only result from an event that rapidly puts the fissile materials into a more reactive (and/or more moderated) geometry that has a $\mathrm{k}_{\text {eff }}$ above the critical limit. The resulting peak overpressure and temperature are inversely correlated with the available exit area of the holes in the waste package barrier. For a total opening area of $0.1 \mathrm{~cm}^{2}$ (which is extremely unlikely because the hole is too small to permit enough water to enter and exit the waste package to set up a critical configuration in the first place), the peak overpressure is less than 60 atmospheres and the peak temperature is only $220^{\circ} \mathrm{C}$. Both these parameters are less than the values that the fuel has already experienced in a PWR. Therefore, they are not likely to cause any damage to the waste package barrier or to the fuel cladding, both of which are important in limiting radionuclide release. The radionuclide inventory increment for the transient event itself will be negligible, since the burnup received from the transient criticality is less than $10^{-7} \mathrm{GWd} / \mathrm{MTHM}$ (because of the short duration of the transient), compared with the 5 to $10 \mathrm{GWd} / \mathrm{MTHM}$ possible for a steady-state criticality of 10,000 years.

\section{Immobilized Plutonium Ceramic Waste Form Description}

The immobilized plutonium ceramic waste form is specially designed to be robust with respect to aqueous degradation (corrosion) and to contain enough insoluble neutron 
absorber to prevent any criticality internal to the waste package. The characteristics and long term behavior of this waste form are fairly well understood ${ }^{(4)}$. The chosen ceramic is a titanate-based material similar in concept to $S Y N R O C^{(5)}$ in which the primary actinide-bearing phases are pyrochlore, zirconolite, and brannerite. Approximately 0.9inch thick ceramic disks will be stacked in cans 20 -inches long. Four cans will be inserted into a columnar magazine, and seven of these magazines will be arrayed in a rack assembly in a canister identical to the ones used for disposal of HLW glass at the Defense Waste Processing Facility at the Savanah River Site. Each can of ceramic disks will contain approximately $0.85 \mathrm{~kg}$ of fissile material, so that each canister will contain approximately $24 \mathrm{~kg}$ of fissile material. The remainder of the canister is filled with HLW glass. The weight, heat load, and radiation load (at the time of production) in this waste package are dominated by the HLW glass, so criticality is the only significant risk issue added by the immobilized plutonium.

The waste package used for this co-disposal will contain five canisters. Analyses thus far have been based on the conservative assumption of all five being plutonium-bearing canisters. However, it is now planned that there will be only one plutonium-bearing canister per waste package, with the other four canisters containing only HLW glass. Therefore, the criticality analyses presented here are very conservative relative to the currently planned loading scheme.

\section{Criticality from the Disposal of the Ceramic Waste Form}

As mentioned above, the principal criticality control for the ceramic waste form comes from the gadolinium neutron absorber added during fabrication of the disks. The weaker neutron absorber hafnium also fits nicely into the pyrochlore crystal lattice. Because hafnium is even less soluble than gadolinium, (under all conditions, particularly those anticipated in the repository), so it is added to the ceramic to provide defense-in-depth with respect to criticality control. The potential for criticality within a waste package is determined primarily by the amount of fissile material relative to the amount of neutron absorber present in the package at a given time. If, and when, the waste package breaches, groundwater could then contact, and begin to corrode, the enclosed wasteforms. Under such conditions the waste form can corrode releasing fissile elements and neutron absorber. Since these fissile materials and neutron absorbers are relatively insoluble, they will mostly remain in place as altered waste form or immediately precipitate in some mineral form, under most chemical conditions.

The solubility and mobilization of plutonium could be enhanced by the formation of colloids. However, neglecting this potential for increased effective solubility is conservative with respect to internal criticality, since mobilized plutonium can be removed from the waste package. In considering external criticality, the higher plutonium effective solubility could result in higher concentration of plutonium in certain external configurations. Hence, the conservative calculation of external criticality should use a source term that accounts for possible colloidal transport of plutonium. 
The neutron absorber hafnium is even less soluble than the fissile material; therefore it will remain in the waste package long after the fissile material has been transported out. However, gadolinium, the more effective neutron absorber, becomes relatively soluble under some chemical conditions (particularly $\mathrm{pH}<6$ ) and could eventually be preferentially flushed from the waste package. The geochemistry part of these studies identified the degradation rates for the waste form, HLW glass, and steel that could lead to low $\mathrm{pH}$, and consequently a significant loss of gadolinium.

The largest loss of gadolinium could occur when the ceramic and stainless steel of waste package corrode at similar rates, and both corrode much faster than the HLW. Under these conditions, the corrosion of the steel may produce chromic acid, which will lower the $\mathrm{pH}$ of the solution in the waste package as long as the glass degrades too slowly to release alkalinity at a high enough rate to neutralize this acid. If this process results in a lower $\mathrm{pH}$, it will enhance the solubility of gadolinium relative to plutonium. The fact that the glass is expected to degrade faster than the stainless steel or ceramic makes this maximum-gadolinium-loss scenario extremely unlikely. Furthermore, no degradation of the ceramic is expected to occur at all in the repository for many thousands of years after emplacement, at which time a significant fraction of the plutonium-239 will have decayed to uranium-235. Uranium is much more soluble than plutonium under these conditions, and will be removed from the waste package along with the gadolinium, thus reducing the possibility of a criticality.

Internal criticality is not credible for fully degraded configurations (defined as having a uniform distribution of fissile material and neutron absorber throughout the waste package with varying degrees of neutron absorber loss from the waste package). The maximum gadolinium loss predicted by the geochemistry calculations, under the worstcase degradation rate conditions, is $78 \%$. Even this worst case of gadolinium loss has a $\mathrm{k}_{\text {eff }}$ of less than 0.5 .

Even though the loss of all the gadolinium from the waste package is an incredible event, it is still worthwhile to evaluate the defense-in-depth provided by the virtually insoluble hafnium, most of which will remain in the waste package for upwards of one million years. Figure 2 shows the minimum amount of hafnium (as a percent of the amount of hafnium initially present) required to maintain sub-criticality as a function of time after waste package breach, under the incredible assumption of loss of all gadolinium. In addition to showing that the hafnium alone will provide sufficient neutron absorption to prevent criticality, this figure also demonstrates that the reactivity in the waste package decreases as the plutonium-239 decays into the less reactive uranium-235 : Beyond 42,000 years, so much plutonium has decayed to $U$ that there is no internal configuration that can go critical, even without the neutron absorbers added into the ceramic waste form. 


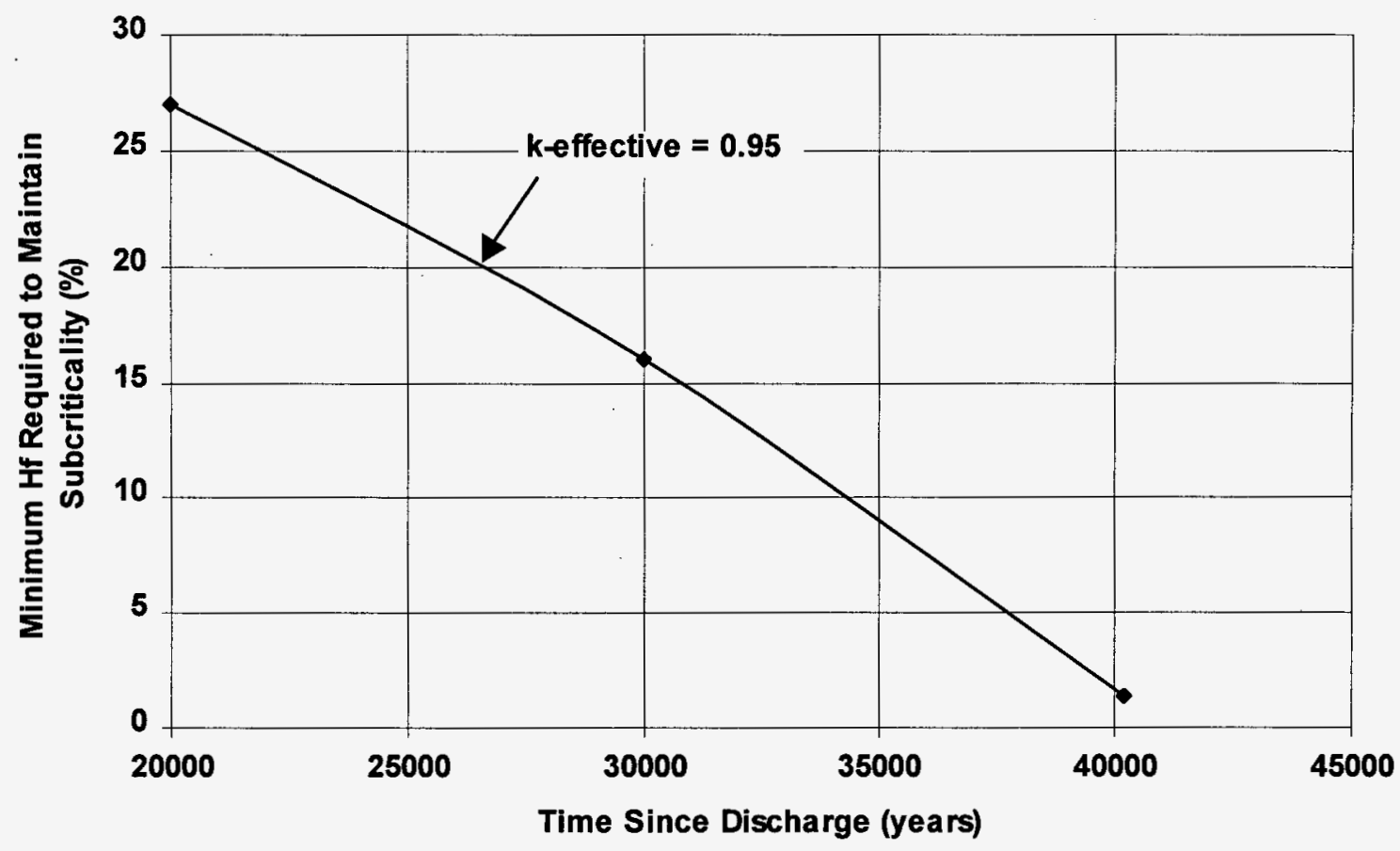

Figure 2. Minimum Hafnium ( $\mathrm{Hf}$ ) Required to Maintain Subcriticality versus Time Since Discharge (Worst-case Configuration with all Gadolinium Already Lost from the Waste Package)

External accumulation of a critical mass from a single waste package requires a high concentration of fissile material in the source term that flows out of the waste package. This high fissile concentration can only occur at a high ceramic aqueous degradation rate (at least 10 times larger than the current abstraction of the experimental data provided by Shaw 1999). Additional unlikely conditions required for the high source term fissile concentration are a high $\mathrm{pH}$ (produced by the rapid simultaneous degradation of the HLW glass), an oxidizing environment (high oxygen fugacity) to maintain plutonium and uranium in a predominantly hexavalent state in solution, and a high concentration (fugacity) of carbon dioxide necessary to supply the carbonates that form the soluble solution species of the fissile elements (plutonium or uranium). Even with this unlikely occurrence, there are a number of additional unlikely conditions required before a critical mass can accumulate in the drift or the host rock. Estimates of the probability of occurrence of such conditions show the total criticality probability to be well below 1 in 100,000 years.

\section{References}

1. U.S. Department of Energy, 2000. Record of Decision for the Surplus Plutonium Disposition Final Environmental Impact Statement, Washington, D.C.

2. CRWMS M\&O 2000. Waste Package Related Impacts of Plutonium Disposition Waste Forms in a Geologic Repository. TDR-EBS-MD-000003, REV 01. Las 
Vegas, Nevada: CRWMS M\&O Contractor.

3. Westinghouse Electric Corporation 1998. Plutonium Disposition Study, Implementation of Weapons Grade MOX Fuel in Existing Pressurized Water Reactors. DOE/SF/19683-7, Rev. 1. Pittsburgh, Pennsylvania: Westinghouse Electric Corporation. TIC: 245436.

4. Shaw, H., ed. 1999. Plutonium Immobilization Project Input for Yucca Mountain Total Systems Performance Assessment. PIP 99-107. Livermore, California:

Lawrence Livermore National Laboratory. TIC: 245437, PIP-99-107.

5. Ringwood, A.E., S.E. Kesson, K.D. Reeve, D.M. Levins, and E.J. Ramm. 1988, SYNROC, in Radioactive Waste Forms for the Future, eds. W. Lutze and R.C. Ewing. Elsevier Science Publishers, New York, pp233-334. 